\title{
Parecer da BRASPEN sobre prescrição de volume, consistência e suplemento nutricional no paciente disfágico
}

BRASPEN's position on volume prescription, consistency and nutritional supplement in the dysphagic patient

DOI: 10.37111/braspenj.AE2019344002

Maria de Fátima Lago Alvite

Silvia Maria Fraga Piovacari²

Diana Borges Dock Nascimento ${ }^{3}$
"Dispõe sobre prescrição de consistência alimentar, volume e suplemento nutricional no que diz respeito à atuação do Fonoaudiólogo e atuação do Nutricionista ao paciente disfágico"

Os Comitês de Fonoaudiologia e Nutrição, no uso de suas atribuições regimentais,

CONSIDERANDO a Lei n 6.965, de 9 de dezembro de 1981, que dispõe sobre a regulamentação da profissão de Fonoaudiólogo;

CONSIDERANDO o que estabelece o Código de Ética da Fonoaudiologia, aprovado pela Resolução No 305 de 2004, do Conselho Federal de Fonoaudiologia;

CONSIDERANDO a RESOLUÇÃO CFFa n 382, de 20 de março de 2010, que dispõe sobre o reconhecimento das especialidades em Fonoaudiologia Escolar/Educacional e Disfagia pelo Conselho Federal de Fonoaudiologia, e dá outras providências;

CONSIDERANDO a RESOLUÇÃO CFFa n 383, de 20 de março de 2010, que dispõe sobre as atribuições e competências relativas à especialidade em Disfagia pelo Conselho Federal de Fonoaudiologia, e dá outras providências;
Aceito para publicação

9 de dezembro de 2019

\section{Endereço para correspondência: \\ Fátima Lago \\ Rua Abilio Soares, 233, Conjunto 144 \\ São Paulo / SP - CEP 04005-000}

\section{Submissão}

17 de agosto de 2019 
CONSIDERANDO a RESOLUÇÃO CFFa n 492, de 7 de abril de 2016, que dispõe sobre a regulamentação da atuação do profissional fonoaudiólogo em disfagia e dá outras providências;

CONSIDERANDO o Parecer CFFa n ${ }^{\circ}$ 40, de 18 de fevereiro de 2016, que dispõe sobre a participação do Fonoaudiólogo na Equipe Multidisciplinar de Terapia Nutricional;

CONSIDERANDO O Parecer CRFa-4 ${ }^{a}$ Região $n^{\circ}$ 003/2015, que dispõe sobre a atuação fonoaudiológica na área hospitalar privada, pública e filantrópica e em atendimento domiciliar e dá outras providências;

CONSIDERANDO o Anexo I da RESOLUÇÃO - RCD N 63, de 6 de julho de 2000 da Agência Nacional de Vigilância Sanitária que prevê as atribuições da Equipe Multiprofissional de Terapia Nutricional (EMTN) para a prática da Terapia Nutricional Enteral (TNE);

E ainda que prevê as atribuições do nutricionista no seu item 7.4. Acompanhar a evolução nutricional do paciente em $\mathrm{TNE}$, independente da via de administração, até alta nutricional estabelecida pela EMTN e 7.5. Adequar a prescrição dietética, em consenso com o médico, com base na evolução nutricional e tolerância digestiva apresentadas pelo paciente.

CONSIDERANDO a RESOLUÇÃO CFN Nº 600, DE 25 de fevereiro de 2018. Dispõe sobre a definição das áreas de atuação do nutricionista e suas atribuições, indica parâmetros numéricos mínimos de referência, por área de atuação, para a efetividade dos serviços prestados à Sociedade e dá outras providências.

LXI. Prescrição Dietética - atividade privativa do nutricionista que compõe a assistência prestada aos clientes/pacientes/usuários em ambiente hospitalar, ambulatorial, consultório ou em domicílio que envolve - plano alimentar, devendo ser elaborada com base nas diretrizes estabelecidas no diagnóstico de nutrição, devendo conter data, valor energético total (VET), consistência, macro e micronutrientes, fracionamento, assinatura seguida de carimbo, número e região da inscrição no Conselho Regional de Nutricionistas (CRN) do nutricionista responsável pela prescrição.

CONSIDERANDO a RESOLUÇÃO CFN N`304 DE 26 de dezembro de 2003, que dispõe sobre critérios para a prescrição dietética na área de Nutrição Clínica e dá outras providências;
CONSIDERANDO a RECOMENDAÇÃO CFN Nº 004 DE 21 de fevereiro de 2016 sobre prescrição de suplementos nutricionais;

CONSIDERANDO a RESOLUÇÃO CFN N ${ }^{\circ} 390$, DE 27 de outubro de 2006, que regulamenta a prescrição de suplementos nutricionais pelo nutricionista e dá outras providências;

Art. 1ํㅡ Compete ao nutricionista a prescrição dietética, como parte da assistência hospitalar, ambulatorial, em consultório de nutrição e dietética e em domicílio.

Art. 2ำ A prescrição dietética deve ser elaborada com base nas diretrizes estabelecidas no diagnóstico nutricional.

Art. 60 $\bigcirc$ nutricionista, ao realizar a prescrição dietética, deverá:

I. considerar o cliente-paciente globalmente, respeitando suas condições clínicas, individuais, socioeconômicas, culturais e religiosas;

II. considerar diagnósticos, laudos e pareceres dos demais membros da equipe multiprofissional, definindo com estes, sempre que pertinente, os procedimentos complementares à prescrição dietética;

CONSIDERANDO a Resolução CFN No 599, de 25 de fevereiro de 2018, que aprova o Código de Ética e Conduta do Nutricionista e dá outras providências (revoga a Resolução No 334/2004):

Conclui-se que:

\section{1 - Ao profissional FONOAUDIÓLOGO compete:}

1.1 - Identificar os indivíduos com risco para disfagia e sugerir à Equipe Multiprofissional de Terapia Nutricional o encaminhamento destes indivíduos para avaliação fonoaudiológica;

1.2 - Avaliar a biomecânica da deglutição;

1.3 - Definir o diagnóstico fonoaudiológico da fisiopatologia da deglutição;

1.4 - Solicitar exames complementares que auxiliam no processo diagnóstico e terapêutico dos distúrbios de deglutição;

1.5 - Colaborar, junto à equipe, na indicação de colocação e retirada da via alternativa de alimentação, quando identificado o risco ou presença de disfagia e esclarecer a dificuldade que algumas vias alternativas podem oferecer na biomecânica da deglutição;

1.6 - Realizar o tratamento - habilitação/ reabilitação/ compensação/adaptação/gerenciamento - dos distúrbios da deglutição; 
1.7 - Prescrever a consistência alimentar, o volume, o ritmo de oferta, os utensílios, as manobras e posturas necessárias para a administração da dieta via oral de forma segura até restabelecer o mecanismo fisiológico normal da deglutição ou o limite terapêutico de acordo com a patologia de base e condições clínicas individuais;

1.8 - Prescrever espessante para adequação das consistências do alimento até restabelecer o mecanismo fisiológico normal da deglutição ou o limite terapêutico de acordo com a patologia de base e condições clínicas individuais;

1.9 - Orientar o paciente, familiar ou responsável legal e cuidador formal quanto aos cuidados necessários na atenção à disfagia orofaríngea, no sentido de maximizar a deglutição nutritiva funcional e minimizar os riscos para a saúde;

1.10 - Orientar equipe multidisciplinar para identificação do risco da disfagia, principalmente a equipe de nutrição e a equipe multidisciplinar de terapia nutricional (EMTN);

1.11 - Avaliar os parâmetros cardiorrespiratórios fisiológicos durante a função da deglutição e relacionados à função da deglutição, como frequência respiratória, frequência cardíaca, ausculta cervical dos ruídos da deglutição e saturação de oxigênio, devido ao risco de complicações pulmonares ocasionadas pela disfagia.

\section{2 - O profissional NUTRICIONISTA é o responsável por:}

Prescrição Dietética - atividade privativa do nutricionista que compõe a assistência individualizada prestada aos pacientes na prevenção, manutenção e promoção da saúde em ambiente hospitalar, ambulatorial, consultório, ILPI e em domicílio que envolve o plano alimentar, devendo ser elaborada com base nas diretrizes estabelecidas no diagnóstico nutricional, devendo conter data, valor energético total (VET), consistência, macro e micronutrientes, fracionamento, assinatura seguida de carimbo, número e região da inscrição no Conselho Regional de Nutricionistas (CRN) do nutricionista responsável pela prescrição.

\subsection{Realizar a prescrição dietética considerando:}

2.1.1 A condição nutricional do paciente que deverá ser realizada com base nos protocolos e diretrizes estabelecidas;

2.1.2 $\bigcirc$ paciente globalmente, respeitando suas condições clínicas, individuais, socioeconômicas, culturais e religiosas;
2.1.3 A tolerância e aceitabilidade da dieta oral principalmente no que se refere a preferências, condições de mastigação, deglutição e absorção;

2.1.4 Diagnósticos, laudos e pareceres dos demais membros da equipe multiprofissional, definindo com estes, sempre que pertinente, os procedimentos complementares à prescrição dietética;

2.2 Ao realizar a prescrição de suplemento nutricional, o nutricionista deverá considerar além dos itens mencionados para a prescrição dietética:

2.2.1 Adequação do consumo alimentar;

2.2.2 Definição do período de utilização da suplementação oral;

2.2.3 Reavaliação sistemática do estado nutricional e do plano alimentar;

2.2.4 A prescrição deve apresentar o esquema posológico, ou seja, a indicação de via de administração, dose, horário de administração e tempo de uso;

2.2.5 Na prescrição da suplementação nutricional, o nutricionista não deverá manifestar preferência de marcas, havendo necessidade de mencioná-las, deverá indicar várias alternativas oferecidas pelo mercado, em conformidade com o parágrafo único, do art. 22, da Resolução CFN n³34/2004.

\section{Considerações finais:}

Compete ao fonoaudiólogo a avaliação da biomecânica da deglutição, a prescrição do volume seguro por oferta, da consistência dos alimentos e dos líquidos espessados para administração via oral segura, até restabelecer o mecanismo fisiológico normal da deglutição ou limite terapêutico de acordo com a patologia de base e condições clínicas individuais.

Compete ao fonoaudiólogo realizar o tratamento - habilitação/ reabilitação/ compensação/ adaptação/gerenciamento - dos distúrbios da deglutição.

Compete ao nutricionista diante dos pacientes disfágicos, a avaliação e diagnóstico nutricional, a prescrição de suplementos nutricionais e a prescrição dietética. Deverá considerar que a prescrição dietética de suplementos nutricionais não poderá ser realizada de forma isolada, devendo fazer parte da correção do padrão alimentar, considerando as possíveis interações entre estes e os alimentos e fármacos, bem como para o melhor aproveitamento biológico da dieta prescrita. 